\title{
An Evaluation of DEMATEL-EVM based Method for the Demonstration Projects of Water Environment Assessment
}

\author{
Wang $\mathrm{Lu}^{1}$, Zhang Jixiang ${ }^{1} \&$ Wang Yanhong ${ }^{2}$ \\ ${ }^{1}$ School of Economics and Management, Nanjing University of Aeronautics and Astronautics, Nanjing, China \\ ${ }^{2}$ School of Geographic Science, Nanjing Normal University, Nanjing, China \\ Correspondence: Wang Lu, School of Economics and Management, Nanjing University of Aeronautics and \\ Astronautics, No. 29 Jiang Jun Road, Jiang Ning District, Nanjing. Tel: 1-325-528-0806. Email: \\ 358338336@qq.com
}

Received: December 8, 2016

Accepted: December 20, 2016

Online Published: January 19, 2017

doi:10.5539/emr.v6n1p39

URL: http://dx.doi.org/10.5539/emr.v6n1p39

\begin{abstract}
The existing methods of the water environmental quality assessment generally focus on the environmental characteristics, and fail to cover the core demands of ecological demonstration project. These methods lack a comprehensive analysis of sustainable development and maintenance capabilities. Also, the subjective analysis and computing of weight furthermore leads to unstable output. This paper is written in attempt to raise a set of assessment systems and methods to evaluate the demonstration projects of water environment. With the helping of establishing a complete quality evaluation index system of water environment demonstration project, the research approaches are based on the model of subjective and objective comprehensive weighting evaluation of DEMATEL-EVM. Through this method, it is able to analyze the key elements scientifically, which influence the water environmental project, finally makes the assessment more convincible.
\end{abstract}

Keywords: water environment, demonstration project, the indicator system, comprehensive weight

\section{Introduction}

\subsection{Research Situation of Evaluation of Water Environment Demonstration Projects}

For now, theories of assessments of water environment demonstration projects are still in the gradually perfect stage. Most of assessments applied in the water pollution treatment use the fuzzy comprehensive evaluation method, which is the combination of Analytic Hierarchy Process (AHP) and DEMATEL. The emphasis of them mostly only focuses on the evaluation of water quality index pollution level. However, it is difficult to achieve an objective evaluation of the running of projects merely depended on the evaluation of water pollution treatment, because large demonstration projects also involve other factors, like ecological and economic benefits. The results of water pollution treatment should be evaluated comprehensively according to the improvement of ecological rehabilitation, national economic benefits and many other standards.

On the other hand, although the current large projects evaluation system can cover the whole construction stage and zoom analyze every node in the projects, projects on environmental governance still lacking mature theoretical system. Without the support of environmental science, the data collection is also in need of objectivity. For most environmental projects, there are still not enough attention paid on the management and monitoring on the later period, as well as the after-evaluation of the projects.

As one of the sixteen national major projects, water pollution treatment, which is in behalf of National Ministry of Environmental Protection, has constantly promoted relative policies on water pollution control. Scholars at home and abroad have taken many discussions on it, their reports and thinking as well as their practices has laid solid theoretical foundation for evaluation works in this field. For building a scientific evaluation index system, this paper referred to abundant literature in the course of study, tried to discard the dross and select the essence.

The unceasingly practice of environmental treatment projects promoted the crossing development of multi subjects and the initial organic integration of environment and projects. As an important part of project evaluation index, economic index should be evaluated in two parts: engineering and national economy. The current major projects can provide numerous references and evidences for macroeconomic evaluation index in this paper. The literature search mainly focuses on projects like Three Gorges Project and South-North Water 
Transfer Project. According to Cheng Hui (2015), Wang Bo (2009) et al., apart from engineering controls during the construction stage, many government-led major projects will highlight the quality assurance system and promote measures on quality management and test standards. Therefore, project evaluation from the perspective of management not only considers the construction, but also can provide suggestions for the later monitoring and maintenance.

\subsection{Methods of Analyzing Model Based on DEMATE-EVM}

The research method applied in this paper is a combination of Decision Making Trial and Evaluation Laboratory (DEMATEL) and Entropy Value Method (EVM), which can analyze the evaluation index based on the objective and subjective weighting method. Then, policy makers' subjectivity could be lessened and their preference could be emphasized during the evaluation.

In order to deal with the logical relationships between different elements better, research normally would employ DEMATEL for complex systems. The central idea is to produce a synthetic matrix through construction and standardization of direct matrix, which can quantify the impact, cause and centrality between elements, finally to confirm the importance of every factor in the project.

The entropy of this research is information entropy, which means it takes in related concepts of information theory. Information entropy is used to measure the amount of information through the disordering level of numerical response. Its principle may summarize is: the smaller the entropy weight of one index, the smaller the disordering level of the system. In other words, the more information this index carries, the greater influence on decision making. As the distance between indexes gets longer, the influence on the evaluation will become bigger. When the distance is 0 , the influence of this index on evaluation can often be ignored.

According to Zhou, Sun and Ren (2005), Meng and Hu (2009), entropy mainly uses data fluctuation of every index to calculate index balance. Therefore, this method is also can be applied in the disordering measurement of the system. Because of the complexity and variability of the water environment, project evaluation needs to collect correlation data in different periods or locations to analyze the rationality of the evaluation index. Given there is large amount of data could be involved in the evaluation system, the introduction of EVM is of practical meaning to the construction of comprehensive evaluation index system.

Here are the detailed steps needed to calculate index weight:

The first step is to build a quality evaluation index system for demonstration projects. Secondly, data should be summarized through expert estimation. Then, subjective weight should be given to first and second level index. Thirdly, to select time node and collect relevant second level index data according to different periods in the project from the lake buffer zone ecological construction projects. Last, to calculate the final combination weight based on the further treatment of second level index from the subjective and objective weights.

Targeted at subjective and objective weights, this paper applied formulas of sum of squares with minimum errors to find the best combination. Assume that $w^{*}$ is the final combination weight, $w^{s}$ is the subjective weight based on DEMEATEL and $w^{t}$ is the objective weight based on EVM. Through the liner combination of these three, the percentage of subjective weight can be defined as $\beta$, and objective weight percentage is $(1-\beta)$, the linear relationship is:

$$
w_{j}^{*}=\beta w_{j}^{s}+(1-\beta) w_{j}^{t}
$$

Since the object function is here, the sum of squares of deviations of subjective weight and combination weight, objective weight and combination weight can be taken as objects to calculate the minimal value:

$$
\min =\sum_{j=1}^{m}\left[\left(w_{j}^{*}-w_{j}^{s}\right)^{2}+\left(w_{j}^{*}-w_{j}^{t}\right)^{2}\right]
$$

According to linear combination, $\beta=0.5$ can be derived, which is consistent with general conclusions, therefore the combination weight of every index is:

$$
w_{j}^{*}=0.5 w_{j}^{s}+0.5 w_{j}^{t}
$$




\section{Quality Evaluation Index System of Water Environment Demonstration Projects}

Water environment treatment project is a long-term, large-scare and multi-periods ecologic project. Therefore, the construction of evaluation index system is able to reflect the dynamic, comprehensive and hierarchical structure of the project. Together with evaluation theory of regional ecologic system, this paper can be divided in to four parts: ecological environment index, maintenance index, benefit index and sustainability index.

Benefit and sustainability index are used in ecological security evaluation and water pollution treatment demonstration projects and etc. Benefit index can directly reflect the period result of demonstration projects, while sustainability index can inspect the perspective endurance power of projects from social environment policy. On the other hand, ecological environment index can directly reflect the background, difficulty of the project and more or less the process of pollution treatment. Considering the change of time and space of regional water quality, the further adjustments should be improved according to the study of influence of project construction on regional water ecological environment. For this point, maintenance index therefore can be more important to the whole evaluation of completed projects.

The influence of second level index on regional water environment could be more detailed. In order to avoid the repetition and cross during the index construction, it is important to recognize the various but related factors.

Ecological environment index normally uses wetlands and lakes ecological evaluation theory for reference to select the factors of the highest frequency, such as diversity of phytoplankton, species abundance of benthos, sewage drainage standard and soil quality index. As for the detailed data collection, it is suggested to take GHZBI for reference to select TN, TP, PPC index to test.

Maintenance index is a reflection of the rationality of project, especially for the later maintenance for the promotion of public facilities, conclusion of resources; it will show difference in different projects or different periods of one project. And these differences are conducive for the application of this index in the linear and parallel comparison. Many current evaluation systems do not do targeted analysis on the later maintenance of project. However, many large projects, especially environment treatment projects, have shortcomings on the management. Therefore, maintenance evaluation is good for the maturity of the whole project construction, the improvement of qualities of participants and efficiency. The system construction in this paper collected and filtered a large amount of data, and believed that above factors and project participation mechanism is the best representation of maintenance evaluation index.

Benefit index is mainly used in reflecting regional economic social development. Public benefit of environment project means that the treatment of water environment can improve domestic living and promote the development of economic and social culture. This index is not only used in project and environment itself, but also the mutual influence between regional ecological and social environment. Therefore, factors included pollution reduction target, value added in agriculture and aquaculture should be put into evaluation. Most projects examine the economic benefits and calculate the data according to techno-economic analysis, while ecological projects tend to focus on social benefits for its particularity, to optimize regional environment, improve added value of travelling and show transcultural aesthetics.

For now, China's lakeside zones commonly are in recession. That is why most current ecological treatment projects are about lakeside water quality ecological system. With all that said, based on the analysis of the particularity of water environment ecological demonstration projects, the analysis of water environment evaluation should take account of system of ecological environment, public benefit of environment projects, maturity of index system and some other factors. It is important to follow the major five principles: systematicness, independence, science, flexibility and comparability. Initially build a quality evaluation system of water ecological demonstration system after referring widely to experts. See the caption for Figure 1. 


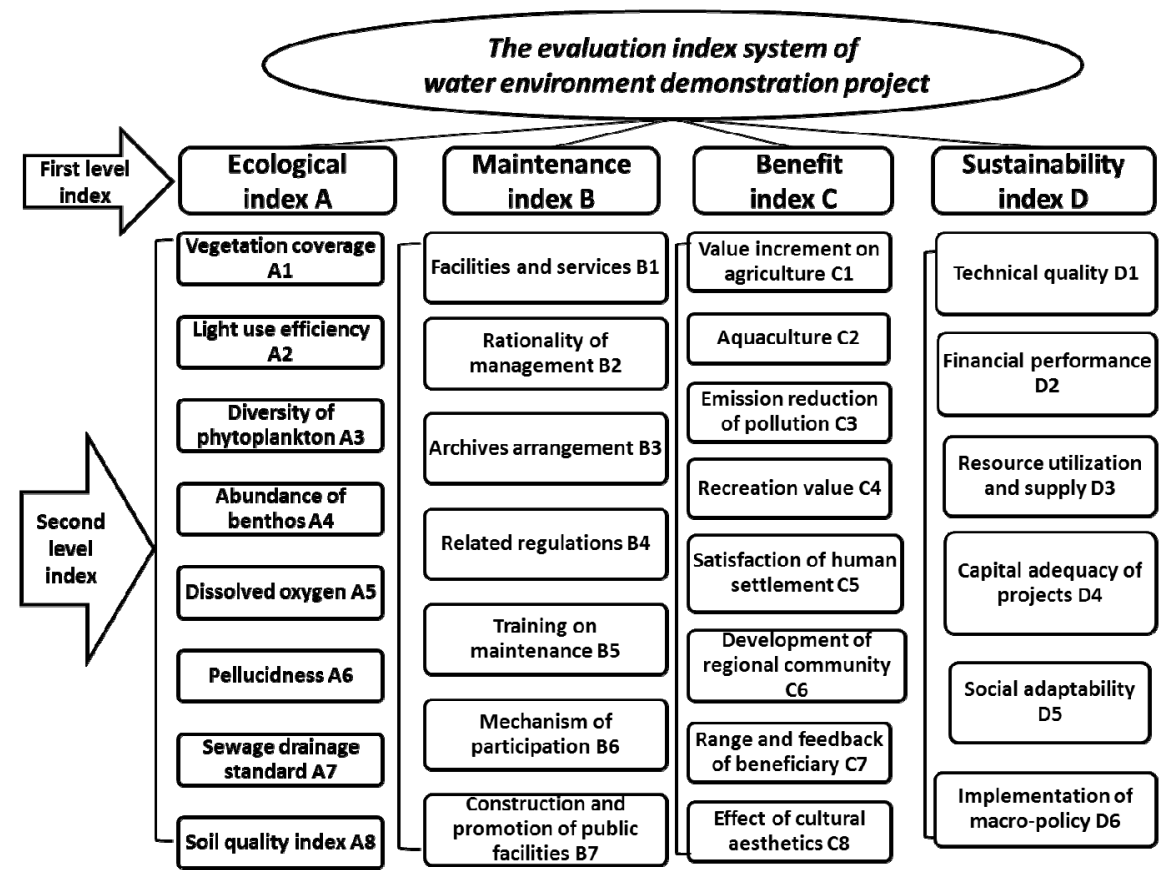

Figure 1. The evaluation index system of water environment demonstration project

\section{Evaluation Index System Based on DEMATEL Method}

DEMATEL aims at finding out the correlation between factors in index system and collecting data through expert advice, questionnaires and rates. Then it can have a better judgment on the science of the system construction and the utility and rationality of index.

According to the definition of laboratory decision analysis, centrality and cause of every factor can be calculated through the combination of graph theory and matrix. Through the further analysis of the importance of this factor in system, the whole system can be analyzed. This method is involved in four calculated value: impact A, affected impact $\mathrm{B}$, centrality $\mathrm{M}$ and cause $\mathrm{R}$.

Impact $\mathrm{A}$ is the sum of elements in row, in the comprehensive influence matrix. The comprehensive influence value of this factor is:

$$
A_{i}=\sum_{j=1}^{n} Z_{i j} \quad(1 \leq i \leq n, 1 \leq j \leq n)
$$

Affected impact B is the sum of elements in column in the standardized direct influence matrix. The comprehensive influence value of this factor is:

$$
B_{j}=\sum_{i=1}^{n} Z_{i j} \quad(1 \leq i \leq n, 1 \leq j \leq n)
$$

Centrality $\mathrm{M}$ is the sum of elements in row and elements in column in the comprehensive influence matrix, which can reflect the importance of this factor in the whole system.

$$
M_{i}=A_{i}+B_{i}, \quad i=1,2, \cdots, n
$$

Cause $\mathrm{R}$ is the difference of elements in row and elements in column in the comprehensive influence matrix, which can reflect its influence on other factors.

$$
R_{i}=A_{i}-B_{i}, i=1,2, \cdots, n
$$

After that, the weight of element I can be obtained in the system. 
In order to avoid the mistakes or difference caused by experts' subjectivity, it is suggested to use the five-level scale $(0,1,2,3,4,5)$ to rate the first and second factor of index. Through the application of MATLAB in calculation of the comprehensive influence matrix and the weighted average of many questionnaires, conclusions can be seen in the Table 1 and Table 2, 3, 4, 5. Based on four assay value, impact and importance between indexes can be judged.

Table 1. First class index comprehensive influence relation table

\begin{tabular}{lccccc}
\hline \multicolumn{1}{c}{ Name of first level index } & Impact A & Affected impact B & Centrality M & Cause R \\
\hline Ecological index & A & 4.3661 & 4.5441 & 8.9102 & -0.178 \\
Maintenance index & B & 4.8019 & 4.7041 & 9.506 & 0.0979 \\
Benefit index & C & 5.0715 & 4.7073 & 9.7788 & 0.3643 \\
Sustainability index & D & 4.3555 & 4.6396 & 8.9952 & -0.284 \\
\hline
\end{tabular}

Table 2. Second class of A index comprehensive influence relation table

\begin{tabular}{lccccc}
\hline \multicolumn{2}{c}{ Name of second level index } & Impact A & Affected impact B & Centrality M & Cause R \\
\hline Vegetation coverage & A1 & 6.837433 & 6.5662 & 13.40367 & 0.2712 \\
Light use efficiency & A2 & 6.489167 & 6.612033 & 13.1012 & -0.12287 \\
Diversity of phytoplankton & A3 & 7.6974 & 6.698967 & 14.3964 & 0.998467 \\
Abundance of benthos & A4 & 5.9782 & 6.5837 & 12.56187 & -0.60553 \\
Dissolved oxygen & A5 & 8.058933 & 6.6804 & 14.73933 & 1.3785 \\
Pellucidness & A6 & 8.105433 & 6.779767 & 14.8852 & 1.325667 \\
Sewage drainage standard & A7 & 5.345867 & 6.391567 & 11.73743 & -1.04567 \\
Soil quality index & A8 & 4.012933 & 6.212667 & 10.22567 & -2.19973 \\
\hline
\end{tabular}

Table 3. Second class of B index comprehensive influence relation table

\begin{tabular}{|c|c|c|c|c|c|}
\hline Name of second level index & & Impact A & $\begin{array}{c}\text { Affected impact } \\
\text { B }\end{array}$ & Centrality M & Cause R \\
\hline Facilities and services & $\mathrm{B} 1$ & 6.060367 & 5.942567 & 12.00293 & 0.1178 \\
\hline Rationality of management & B2 & 7.915267 & 6.2366 & 14.1519 & 1.678667 \\
\hline Archives arrangement & B3 & 4.163533 & 5.809833 & 9.9734 & -1.6463 \\
\hline Related regulations & B4 & 6.3012 & 6.197467 & 12.49867 & 0.103733 \\
\hline Training on maintenance & B5 & 6.590733 & 6.287867 & 12.8786 & 0.3029 \\
\hline Mechanism of participation & B6 & 6.411833 & 6.213567 & 12.6254 & 0.198267 \\
\hline Construction and promotion of public facilities & B7 & 5.267767 & 6.022767 & 11.29053 & -0.755 \\
\hline
\end{tabular}

Table 4. Second class of $\mathrm{C}$ index comprehensive influence relation table

\begin{tabular}{lccccc}
\hline \multicolumn{1}{c}{ Name of second level index } & & Impact A & Affected impact B & Centrality M & Cause R \\
\hline Value increment on agriculture & $\mathrm{C} 1$ & 5.174633 & 6.8411 & 12.01573 & -1.6665 \\
Aquaculture & $\mathrm{C} 2$ & 6.4882 & 6.967633 & 13.45587 & -0.47943 \\
Emission reduction of pollution & $\mathrm{C} 3$ & 8.873 & 7.106133 & 15.97913 & 1.7669 \\
\hline
\end{tabular}




\begin{tabular}{lccccc}
\hline Recreation value & C4 & 6.8805 & 7.0718 & 13.9523 & -0.1913 \\
$\begin{array}{l}\text { Satisfaction of human settlement } \\
\begin{array}{l}\text { Development of regional } \\
\text { community }\end{array}\end{array}$ & C5 6 & 7.415833 & 7.206433 & 14.62227 & 0.209467 \\
$\begin{array}{l}\text { Range and feedback of beneficiary } \\
\text { Effect of cultural aesthetics }\end{array}$ & C7 & 7.992633 & 7.2063 & 15.199 & 0.786333 \\
\hline
\end{tabular}

Table 5. Second class of D index comprehensive influence relation table

\begin{tabular}{lccccc}
\hline \multicolumn{2}{c}{ Name of second level index } & Impact A & Affected impact B & Centrality M & Cause R \\
\hline Technical quality & D1 & 6.4311 & 5.8052 & 12.23623 & 0.6259 \\
$\begin{array}{l}\text { Financial performance } \\
\text { Resource utilization and }\end{array}$ & D2 & 5.6769 & 5.8483 & 11.5252 & -0.1714 \\
$\begin{array}{l}\text { supply } \\
\text { Capital adequacy of projects }\end{array}$ & D3 & 5.988667 & 6.0168 & 12.00543 & -0.02813 \\
$\begin{array}{l}\text { Social adaptability } \\
\begin{array}{l}\text { Implementation of } \\
\text { macro-policy }\end{array}\end{array}$ & D5 & 5.905867 & 6.0748 & 11.9806 & -0.16893 \\
\hline
\end{tabular}

From the impact, maintenance index and benefit index have great influence on other indexes. That is to say, apart from the attention needed to pay to the result of project, it is also very important for an environment demonstration project to pay attention to facilities and its construction of regulation management. Mature monitoring and maintenance measures can bring longer life to ecological environment treatment.

For ecological environment, the impact and affected impact of pellucidness index rank the first in different indexes of second level analysis system. That means, pellucidness has a high correlation with other factors in ecological environment. It is the best reflection of the water quality. Furthermore, the quality of water environment ecological system can be improved through the improvement of this data.

While for maintenance index, the rationality of set of management has the highest impact because maintenance and training works are very easy to be influenced by other indexes, which is consistent with the rationality of general benefit index. The local economic development has the most direct impact on the ecological environment. No matter is for pollution caused by human activities, or GDP's support to projects, they are all decided by this factor. Satisfaction of settlement while is the perfect choice for showing the quality of local ecological environment, and it also can be used in reflecting the result of public benefit of projects.

Among sustainability indexes, the national and local policies play the fundamental roles. Besides, the adequacy of running funding for project is the most direct standard for the sustainability of the whole project. Therefore, these two indexes rank the first in their evaluations, which is scientific for multi-questionnaires data gathering.

According to data, pellucidness, rationality of management, emission reduction of pollution and national or local policies respectively rank the first in different index's causes. That is to say, these four factors are in very central and have the highest correlation with other factors. In fact, emission reduction of pollution is not only related to the living quality of residents' economic social activities, but is also related to ecological system. It is an important dimension in linking economy, society and natural environment. The rationality of management is the foundation for the success of a project and the material guarantee for the later maintenance work. In other words, policy controlling from macro level and measure monitoring from the micro level are the most factors for an orderly process of engineering science. To build a good engineering environment, it is necessary to combine government's provisions on emission reduction of pollution and the significance attached to maintenance of projects.

According to the causes of every factor, as causes, vegetation coverage, rationality of management, emission reduction of pollution and pollution and national or local policies are the fundamental motivation for impacting the project; soil quality, archives arrangement, value increment on agriculture and financial performance as 
results, have less influence on other factors. Thus, the improvement of cause factors can fundamentally improve the quality of water environment ecological system.

\section{Water Environment Demonstration Project Evaluation Based on DEMATEL-EVM}

Entropy takes over the single valuedness and extremum property of thermodynamic entropy in the practical application, meanwhile it takes in information theory's concept on data process. According to data fluctuation of every index, to calculate the entropy and then obtain the entropy weight of every index. The basic concept of this method is assuming that there are " $m$ " objects, and every evaluation object has " $\mathrm{n}$ " index. Through the construction of matrix to obtain the matrix $\mathrm{H}$. The definition of entropy of every evaluation index is:

$$
P_{j}=-\left(\sum_{i=1}^{m} f_{i j} \ln f_{i j}\right) / \ln m
$$

In this formula,

$$
f_{i j}=\left(1+h_{i j}\right) / \sum_{i=1}^{m}\left(1+h_{i j}\right)
$$

is the evaluation index "J" of the evaluation target "I". After the calculation of entropy weights of every index.

$$
W=\left(w_{j}\right)_{1 \times n}, w_{j}=\left(1-P_{j}\right) /\left(n-\sum_{j=1}^{n} P_{j}\right)
$$

The central concept of EVM is the utility value of targeted index information. The bigger the utility value is, the greater the impact of this index on the evaluation. EVM can not only calculate the index weight objectively, but also can filter indexes through the observation of the variation of index: when

$$
\sum_{j=1}^{n} w_{j}=1
$$

entropy value is 0 , then is index is useless and can be deleted.

As one of China's five largest freshwater lakes in the Lower Yangtze Region, Taihu Lake also suffers from the water degradation and eutrophication. Because of the rapid development of drainage area economy, the ecological system of Taihu Lake has been damaged seriously, even been degenerated. Led by national policies, Taihu Lake becomes one the "Three Lakes" with special control.

The study and demonstration project of Zhu Shan Bay lakeside buffer ecological construction and function recovering technologies is the major technical project of national "the Twelfth Five-year". As the process of this project, the Zhu Shan Bay lakeside buffer demonstration project has achieved period success. The study data was selected from 2011 to 2014, which nicely fits national "the Twelfth Five-year" plan.

Based on the above index evaluation system, this paper employed DEMATEL-EVM to evaluate the performance of Taihu Lakeside buffer ecological demonstration project and analyze the science gender of construction of index system. Through taking the mode, mean method and Principal Component Analysis, the data collected from questionnaires can be summarized according to its own and targeted value's particularities. Meanwhile, MATLAB can be used to calculate the objective weights of every index. Combination weight can be obtained through the combination of two types of weight, according to

$$
w_{j}^{*}=0.5 w_{j}^{s}+0.5 w_{j}^{t}
$$

The result can been see as follows (Tables 6, 7, 8, 9):

Table 6. Class A index of subjective and objective weighting method weights

\begin{tabular}{lcccc}
\hline \multicolumn{2}{c}{ Name of second level index } & subjective weights & objective weights & Combination weights \\
\hline Vegetation coverage & A1 & 0.129067 & 0.1231 & 0.126083 \\
Light use efficiency & A2 & 0.124633 & 0.1306 & 0.127617 \\
Diversity of phytoplankton & A3 & 0.136467 & 0.1257 & 0.131083 \\
Abundance of benthos & A4 & 0.118833 & 0.1237 & 0.121267 \\
\hline
\end{tabular}




\begin{tabular}{lcccc}
\hline Dissolved oxygen & A5 & 0.140467 & 0.1276 & 0.134033 \\
Pellucidness & A6 & 0.141433 & 0.1232 & 0.132317 \\
Sewage drainage standard & A7 & 0.111467 & 0.1231 & 0.117283 \\
Soil quality index & A8 & 0.0976 & 0.1231 & 0.11035 \\
\hline
\end{tabular}

Table 7. Class B index of subjective and objective weighting method weights

\begin{tabular}{lcccc}
\hline \multicolumn{1}{c}{ Name of second level index } & & subjective weights & objective weights & Combination weights \\
\hline Facilities and services & B1 & 0.138767 & 0.1582 & 0.148483 \\
Rationality of management & B2 & 0.165733 & 0.1397 & 0.152717 \\
Archives arrangement & B3 & 0.115933 & 0.1408 & 0.128367 \\
Related regulations & B4 & 0.146933 & 0.1392 & 0.143067 \\
$\begin{array}{l}\text { Training on maintenance } \\
\text { Mechanism of participation }\end{array}$ & B5 & 0.1518 & 0.1381 & 0.14495 \\
$\begin{array}{l}\text { Construction and promotion of public } \\
\text { facilities }\end{array}$ & B6 & 0.148367 & 0.1384 & 0.143383 \\
\hline
\end{tabular}

Table 8. Class $\mathrm{C}$ index of subjective and objective weighting method weights

\begin{tabular}{|c|c|c|c|c|}
\hline \multicolumn{2}{|l|}{ Name of second level index } & \multirow{2}{*}{$\begin{array}{c}\text { subjective weights } \\
0.106267\end{array}$} & \multirow{2}{*}{$\begin{array}{c}\text { objective weights } \\
0.1248\end{array}$} & \multirow{2}{*}{$\begin{array}{c}\text { Combination weights } \\
0.115533\end{array}$} \\
\hline Value increment on agriculture & $\mathrm{C} 1$ & & & \\
\hline Aquaculture & $\mathrm{C} 2$ & 0.1184 & 0.1259 & 0.12215 \\
\hline Emission reduction of pollution & $\mathrm{C} 3$ & 0.142067 & 0.1256 & 0.133833 \\
\hline Recreation value & $\mathrm{C} 4$ & 0.123167 & 0.1255 & 0.124333 \\
\hline Satisfaction of human settlement & $\mathrm{C} 5$ & 0.128367 & 0.124 & 0.126183 \\
\hline $\begin{array}{l}\text { Development of regional } \\
\text { community }\end{array}$ & C6 & 0.134567 & 0.1253 & 0.129933 \\
\hline $\begin{array}{l}\text { Range and feedback of } \\
\text { beneficiary }\end{array}$ & $\mathrm{C} 7$ & 0.131667 & 0.1246 & 0.128133 \\
\hline Effect of cultural aesthetics & $\mathrm{C} 8$ & 0.1155 & 0.1244 & 0.11995 \\
\hline
\end{tabular}

Table 9. Class D index of subjective and objective weighting method weights

\begin{tabular}{lcccc}
\hline \multicolumn{1}{c}{ Name of second level index } & & subjective weights & objective weights & Combination weights \\
\hline Technical quality & D1 & 0.173033 & 0.1638 & 0.168417 \\
Financial performance & D2 & 0.162833 & 0.1634 & 0.163117 \\
Resource utilization and supply & D3 & 0.1699 & 0.1634 & 0.16665 \\
Capital adequacy of projects & D4 & 0.169867 & 0.1672 & 0.168533 \\
Social adaptability & D5 & 0.147633 & 0.1644 & 0.156017 \\
$\begin{array}{l}\text { Implementation of } \\
\text { macro-policy }\end{array}$ & D6 & 0.176733 & 0.1778 & 0.177267 \\
\hline
\end{tabular}

According to the combination weights, calculate the data that has been processed nondimensional. And then re-evaluate the normalized judgment matrix, obtain the comprehensive quality index of each year in ecological demonstration project of Zhu Shan Bay lakeside buffer, see Table 10. 
Table 10. The comprehensive quality evaluation index of Zhu Shan wan ecological demonstration project

\begin{tabular}{lccccc}
\hline \multicolumn{2}{c}{ Name of first level index } & 2011 & 2012 & 2013 & 2014 \\
\hline Ecological index & $\mathrm{A}$ & 0.454364 & 0.517426 & 0.498487 & 0.511022 \\
Maintenance index & $\mathrm{B}$ & 0.450583 & 0.504972 & 0.487366 & 0.517287 \\
Benefit index & $\mathrm{C}$ & 0.46571 & 0.476946 & 0.509835 & 0.537412 \\
Sustainability index & $\mathrm{D}$ & 0.438669 & 0.487887 & 0.546755 & 0.501306 \\
\multicolumn{1}{c}{ sum } & & 1.809326 & 1.98723 & 2.042443 & 2.067028 \\
\hline
\end{tabular}

The above tables show the gradual improvement of construction quality of this project within four years and the completion of the project are good as the process of construction. The scale effect and ecological benefit of the project are gradually becoming clear. With the guidance of national policies, the rating of project is also increasing. Small fluctuations happened to classification index mainly during 2012 to 2013, the period that ratings of ecological environment and maintenance indexes has decreased. The main reason is the influence of heavy rain in the first half of 2013 on the Jianghuai area on Taihu lake's ecological environment, which caused a decline of the diversity of phytoplankton and other indexes. Furthermore, southern area of Jiangsu has less rain and more droughts, which also has a negative impact on the local economy development. On the other hand, in 2013, government paid more attention on the environment treatment, especially on water projects. Jiangsu invested 18 billion on water environment treatment to make sure the improvement of sustainability index.

Overall, maintenance index has the biggest fluctuation among all, which proves the conclusion from DEMATEL analysis. For a better performance of project and improvement of benefits, it is important to pay attention to maintenance work and form a scientific monitoring system of project. Furthermore, it also can effectively predict the potential risk and changes then strengthen the sustainability of the project.

Affected by the industrial pollution and non-standard emission of sewage, even the water quality test reports from 2012-2014 can still reflect the quality of Taihu Lake to some degrees. According to Taihu Lake Monthly, Water Bulletin and annals, the treatment of Zhushan Bay lakeside buffer can have the opposite effect on the water quality of Taihu Lake every year on different levels. Therefore, the evaluation of this paper is not only targeted at Zhushan Bay project, but also at reflecting the treatment of Taihu Lake.

Taihu Lake is located at the Yangtze River delta, which straddles Jiangsu and Zhejing two provinces. As one of the most important national grain production base, Jiangsu's agricultural land produces a lot of fertilizer and pesticide pollution, which is an important reason of water pollution. Therefore, it is very necessary to launch education and legal supervisor to countryside. In addition, ecological agriculture and bio-control of pests should be advocated. For the sewage emission monitoring work, it should focus on the key section. Meanwhile, in order to minimize the dispersion of sewage and maximize the efficiency of pollution treatment, forewarning and emergency system shall be established in the case of emergency. From macro policies, it is suggested to strengthen the supervision and law enforcement to people living around project area. Behaviors like putting out fishing nets privately, reclaiming breeding, abuse of water plants and so on should prohibited to maintain the stability of ecological environment.

\section{Conclusion}

The result of the methods used in this paper is consistent with the development of Taihu Lake demonstration project. The evaluation can reflect the result and shortcomings of the running of the project, which means the application of DEMATEL-EVM has some certain operability on lakeside buffer ecological project and the result is reliable and practical.

Meanwhile, this method can not only be used in evaluation of different periods of lakeside buffer ecological project, but also can be used in study of different water environment demonstration projects in different areas, which provides basis for the sustainable development and management of the project.

China owns many lakes and rivers, providing important shelters for various aquatic animals and plants. Influenced by environmental issues, water environment treatments obtained great achievements in 20 years led by national policies. Evaluation system is developing more and more professional and the study of water majors is becoming more and more detailed and comprehensive. However, there is still a lot of space for improvement in China's study of water environmental ecological quality evaluation of demonstrated projects because of the lack of a unitized norm. 
Based on the reference to the current water environment evaluation index system, this paper built a comprehensive and targeted water environment demonstrated project quality evaluation index system according to demonstrated project's characteristics. Furthermore, this paper also evaluated the Zhushan Bay lakeside buffer ecological demonstration project in Taihu Lake and provided further suggestions for the ecological treatment works of water environment. The research methods of this paper are very comprehensive and scientific. However, the quantification of detailed index of the evaluation system still needs to be adjusted according to the situation of the project.

\section{References}

Araújo, S. C., Salles, P., \& Saito, C. H. (2008). A case study on qualitative model evaluation using data about river water quality. Ecological Informatics, 3(1), 13-25. https://doi.org/10.1016/j.ecoinf.2007.09.004

Lucchi, E. (2016). Simplified assessment method for environmental and energy quality in museum buildings. Energy and Buildings, 117, 216-229. https://doi.org/10.1016/j.enbuild.2016.02.037

Mijović, S. R., Vuković, Ž., \& Mažgalj, A. (2006). A pan-European classification of the Skadar lake according to environmental standards. Facta universitatis-series: Physics, Chemistry and Technology, 4(1), 35-43. https://doi.org/10.2298/FUPCT0601035M

Qi, Y., Wen, F., Wang, K., Li, L., \& Singh, S. (2010). A fuzzy comprehensive evaluation and entropy weight decision-making based method for power network structure assessment. International Journal of Engineering, Science and Technology, 2(5), 92-99. https://doi.org/10.4314/ijest.v2i5.60126

Sharma, V., Sharma, V., Dixit, A. R., Dixit, A. R., Qadri, M. A., \& Qadri, M. A. (2016). Empirical assessment of the causal relationships among lean criteria using DEMATEL method. Benchmarking: An International Journal, 23(7), 1834-1859. https://doi.org/10.1108/BIJ-08-2014-0078

Veliu, A., \& Berisha, V. (2015). Assessment of Water Quality Parameters during the Environmental Impact Assessment Process for Industrial Complex of NewCo Ferronikeli. Journal of International Environmental Application and Science, 10(4), 470.

Vighi, M., Finizio, A., \& Villa, S. (2006). The evolution of the environmental quality concept: From the US EPA Red Book to the European Water Framework Directive. Environmental Science and Pollution Research, 13(1), 9-14. https://doi.org/10.1065/espr2006.01.003

Zhang, X. H., Xie, F., Wee, H. L., Thumboo, J., \& Li, S. C. (2008). Applying the Expectancy-Value Model to Understand Health Values. Value in Health, 11(s1), S61-S68. https://doi.org/10.1111/j.1524-4733.2008.00368.x

Zou, Z. H., Yi, Y., \& Sun, J. N. (2006). Entropy method for determination of weight of evaluating indicators in fuzzy synthetic evaluation for water quality assessment. Journal of Environmental Sciences, 18(5), 1020-1023. https://doi.org/10.1016/S1001-0742(06)60032-6

\section{Copyrights}

Copyright for this article is retained by the author(s), with first publication rights granted to the journal.

This is an open-access article distributed under the terms and conditions of the Creative Commons Attribution license (http://creativecommons.org/licenses/by/4.0/). 